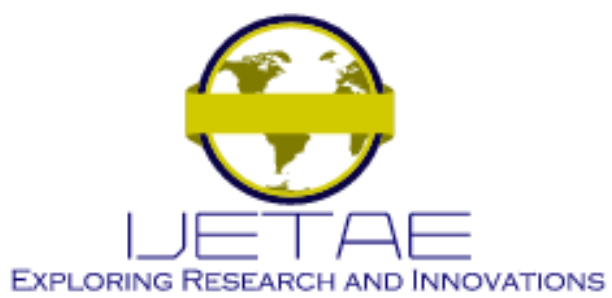

International Journal of Emerging Technology and Advanced Engineering

Website: www.ijetae.com (E-ISSN 2250-2459, Scopus Indexed, ISO 9001:2008 Certified Journal, Volume 12, Issue 01, January 2022)

Manuscript Received: 02 December 2021, Received in Revised form: 04 January 2022, Accepted: 12 January 2022

DOI: 10.46338/ijetae0122_15

\title{
Models and Methods for Improving Performance of Wireless Computer Networks Based on the Decomposition of Lower Layers of the OSI Reference Model
}

\author{
Andriy Dudnik ${ }^{1}$, Ivan Bakhov ${ }^{2}$, Oleksandr Makhovych ${ }^{3}$, Yulia Ryabokin ${ }^{4}$, Oleksandr Usachenko ${ }^{5}$ \\ ${ }^{1,3}$ Taras Shevchenko National University of Kyiv, 60 Volodymyrska str., Kyiv, 01033, Ukraine \\ 2,4,5 Interregional Academy of Personnel Management, 2 Frometivska str., Kyiv, 01039, Ukraine
}

\begin{abstract}
The paper discusses models and methods for improving the performance of wireless computer networks built based on the decomposition of the lower levels of the OSI reference model. A method to improve the performance of networks is suggested, which functionally combines the physical and network layers, which improves its efficiency in marginal reception areas almost twice. A model of the block diagram of a device for improving data transmission quality in marginal reception areas or those with insufficient noise immunity is developed based on the so-called communication quality status monitoring, as well as a model of the block diagram of a wireless adaptive capacity reallocation router based on dynamic channels capacity reallocation, which allows adequately reallocating IS resources depending on traffic and user priority.
\end{abstract}

Keywords - Bluetooth, FIFO discipline, IEEE 802.11, OSI/ISO reference model, wireless computer networks.

\section{INTRODUCTION}

Among the various classes of computer information systems and networks, a special place is held by systems and networks whose transport service is built on using airwaves as a data transmission medium (wireless computer networks). A number of programs have been adopted and are being implemented to ensure creation of such facilities. One of the types of such support consists in creating scientific foundations for building performance wireless computer networks based on modification of the existing classical reference model for open systems interconnection (ISO/OSI RM), according to which most wireless computer networks are designed, created and operated, as well as theoretical analysis and search for optimal methods of modeling, interaction and management of wireless computer networks.
Issues of researching into wireless computer networks, including studying technologies of modeling, management and interaction are covered in works by contemporary scientists S.H. Bunin, M. A. Vynohradov, V. I. Vyshnevskyi, I. A. Zhukov, Yu. P. Zaichenko, M. Ye. Ilchenko, V. H. Olifer, L. O. Uryvskyi, as well as papers by J. Geier, J. Irvine, J. Leary, P. Roshan, V. Stollings, D. Harle and others.

Wireless computer networks are a relatively new type of computer systems used in the national economy and at special facilities; they are characterized by diversity types and high density of information traffic transmitted amidst an intense noise flow, a heterogeneous structure and a large number of integrated network tools with limited capacity.

The paper considers systems that use unlicensed radiofrequency regions, which are typical represented by ISM capacity networks. The peculiarity of the research object lies in the contradiction between the high requirements for the QoS characteristics at the upper layers of the ISO/OSI RM and effectively the very limited values of the lower layers indicators, which form the transport service of a wireless computer network. Another feature of wireless computer networks is represented by the limited computational capabilities of user systems due to the requirement for their mobility.

The real value of performance, the ability to maintain appropriate QoS indicators of a wireless computer network, depends on chosen strategies (technologies) for data preparation and transmission via airwaves. If you choose an ineffective strategy in a network using airwaves, congestion is possible and, as a consequence, an increase in the number of packets transmitted with errors, which generates additional noise in the radio channel [1-6]. 


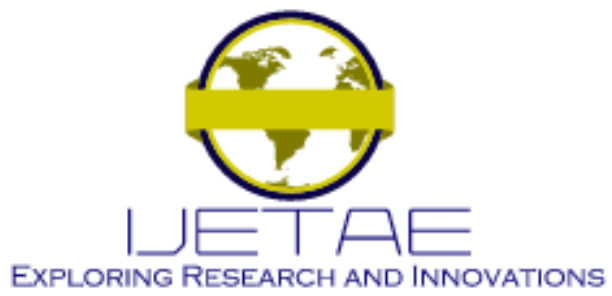

International Journal of Emerging Technology and Advanced Engineering

Website: www.ijetae.com (E-ISSN 2250-2459, Scopus Indexed, ISO 9001:2008 Certified Journal, Volume 12, Issue 01, January 2022)

Classical methods of improving data transmission performance based on buffering, arranging the signaling message stream to control the data transmission speed and using windows, are not sufficient in the context of limited capacity signaling channels: we should find other ways to improve performance of wireless computer networks [7-9].

Thus, the topic of this study dedicated to analysis and search for optimal methods of modeling and developing control and interaction facilities, which allows increasing performance of wireless computer networks, is relevant and of scientific and practical interest.

\section{Problem Statement}

The purpose of this study is to analyze and substantiate the theoretical foundations, as well as to develop models and methods related to raising performance of wireless networks, improving their management tools built according to the reference model of open systems interconnection by modifying interlayer communication.

\section{iII. Presentation Of Basic Material}

The main techniques for control, interaction and performance improvement in wireless information systems and networks have been analyzed. A comparative analysis of the main existing data transmission technologies has been conducted. Based on experimental studies, shortcomings and degrees of freedom to improve control and interaction systems and performance improvement in existing wireless data transmission technologies have been identified. Models of wireless information systems and features of data transmission modeling in a wireless environment have been considered. Analysis and research are conducted relative to the physical layer of the OSI/ISO reference model [10-14].

It has been established that it is sinewaves that are usually used in both analog and digital wireless communication systems, but various types of modulation are used for their information content, first of all amplitude, frequency, and phase modulation. Generally, the modulation process consists in changing the amplitude $D$, frequency $\omega$ or phase $\varphi$ of a harmonic wave, and therefore such waves are also called quasi-harmonic. It has been found that in practice land wireless communication systems do not usually face single obstacles but a whole lot of them in the form of a large number of buildings for cities or woodlands and hills for rural areas.
Therefore, when decimetric and centimeter radio waves propagate along the earth surface, the environment and its electromagnetic parameters have a great influence on the characteristics of the signal. There are many shadow zones, as well as multiple reflection of signals, due to which electromagnetic fields are formed with a rather complex interference structure and sharp spatial changes in the signal strength. Signal attenuation both on obstacles and along communication lines, as well as electrical characteristics of the atmosphere also wield major influence [15-17].

Such a multipath nature of radio wave propagation, when each space point is characterized by the fact that it receives signals from different directions and with different time delays, contributes to multiple interference of signals and their significant distortion. Such distortions exert a considerable impact on the system characteristics if the period of delay exceeds the time of data packet transmission. That is, in computer wireless systems, as in wired systems, the main rule is of great importance, namely that a packet must reach the endpoint before its last character is transmitted. But in case of multidirectional propagation of wireless signals, it is much more difficult to fulfill this condition. Geometric optics models are most often used for wireless systems buildings and small areas, which are usually designed according to Wi-Fi standards [16-20].

A detailed analysis of signal coding methods in wireless networks has been performed.

It has been established that wireless networks use frequency and phase pulse-code modulation with frequency, time, or code division of radio communication channels. When using the method of frequency division of channels FHSS the multichannel operation mode of a network is ensured because depending on to what destination node a data packet is sent, the frequency of the sending station changes by a small amount. For example, for Wi-Fi standard networks, the $2.4 \mathrm{GHz}$ dynamic range is divided into 75 channels with a bandwidth of $75 \mathrm{MHz}$ each. The DSSS code division method is also utilized while using the eleven-character Barker code sequence. Typically, the signal frequency bands for FHSS channels have a higher gain, while the bands for DSSS channels are wider. When implementing specific network protocols for wireless communication between a receiver and a data transmitter, information is exchanged to confirm recognition of a packet this process being called acceptance acknowledgment (another English term -- handshaking) [21]. 


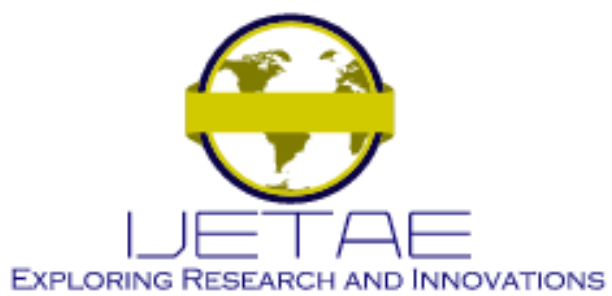

International Journal of Emerging Technology and Advanced Engineering

Website: www.ijetae.com (E-ISSN 2250-2459, Scopus Indexed, ISO 9001:2008 Certified Journal, Volume 12, Issue 01, January 2022)

However, such frequency divided and code divided channels should also be time divided, because in case of simultaneous broadcasting on two or more frequencies, interbeam signal interference (ISI) occurs. In view of this, the well-known method of multiple access with carrier frequency control and collision detection is used for time division of packet forwarding by different communication channels. This method of channel division is called orthogonal frequency division multiplexing -- OFDM, which is implemented in the IEEE 802.11 standard [22].

Using examples of models of wireless ISs having equipment of the IEEE 802.11 standard, the specifics of their design have been considered.

Analysis of the main models and the most well-known modeling tools in terms of their application to model data transmission, relative to the data-link layer of the ISO/OSI reference model made it possible to suggest a universal model that could consider not only the concept of the entire network operation but also operation of its particular sections [23-25].

\section{RESEARCH METHODS}

The conceptual model of a simple version of scatternet (a distributed network with many branches) is represented by an open multiphase queuing system. In terms of classification of the reference model, two lower layers were described. A transaction, which is an indivisible object within a general-purpose simulation system, was generated by a bit moving in the scatternet from the information source to the consumer. Each phase was simulated by QS $G / M / n$ with failures and $F I F O$ discipline. The universal simulation system ensures collection and statistical processing of data on transactions delayed at each point of the model, as well as the rate of failures occurred.

The bit delay time in transmission channels $\left(W_{\text {queue }}\right)$ of this network is determined according to the formula for calculating the queuing delay time of a multichannel delay device:

$$
W_{\text {queиe }}=\frac{1}{\sum_{i=1}^{N} \lambda_{i}} L_{\text {quene }}
$$

where $\lambda$ - the rate of entry of bits transmitted for the $i$-th state;

$L_{\text {queue }}$ - the average number of transmitted bits is determined from the following formula:

$$
L_{\text {queue }}=\frac{\sum_{i=1}^{N} \rho_{i}{ }^{n+1} P_{0}}{n \cdot n !\left(1-\sum_{i=1}^{N} \rho_{i} / n\right)^{2}},
$$

where $n$ - the number of distributed subchannels of wireless data transmission of the Bluetooth network, which in this case are 23;

$P_{0}-$ the likelihood that a subchannel is currently busy is determined by the formula:

$$
P_{0}=\left(1+\frac{\sum_{i=1}^{N} \rho_{i}}{1 !}+\frac{\sum_{i=1}^{N} \rho_{i}}{2 !}+\ldots+\frac{\sum_{i=1}^{N} \rho_{i}^{n}}{n !}+\frac{\sum_{i=1}^{N} \rho_{i}^{n+1}}{n !\left(n-\sum_{i=1}^{N} \rho_{i,}\right)}\right)^{-1}
$$

where $\rho$ - the load on this network of wireless data transmission, determined by the formula:

$$
\rho=\frac{\sum_{i=1}^{N} \lambda_{i}}{\mu}
$$

where $\lambda-$ the rate of bits entry to a data-transmission network in the i-th state;

$\mu$ - bit rate service in a data-transmission network.

Substituting all these values into the formula (1), we obtain the following resulting formula: 


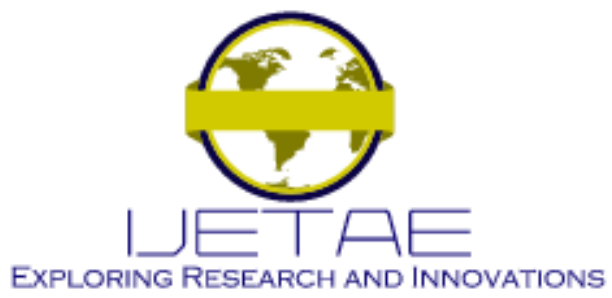

International Journal of Emerging Technology and Advanced Engineering Website: www.ijetae.com (E-ISSN 2250-2459, Scopus Indexed, ISO 9001:2008 Certified Journal, Volume 12, Issue 01, January 2022)

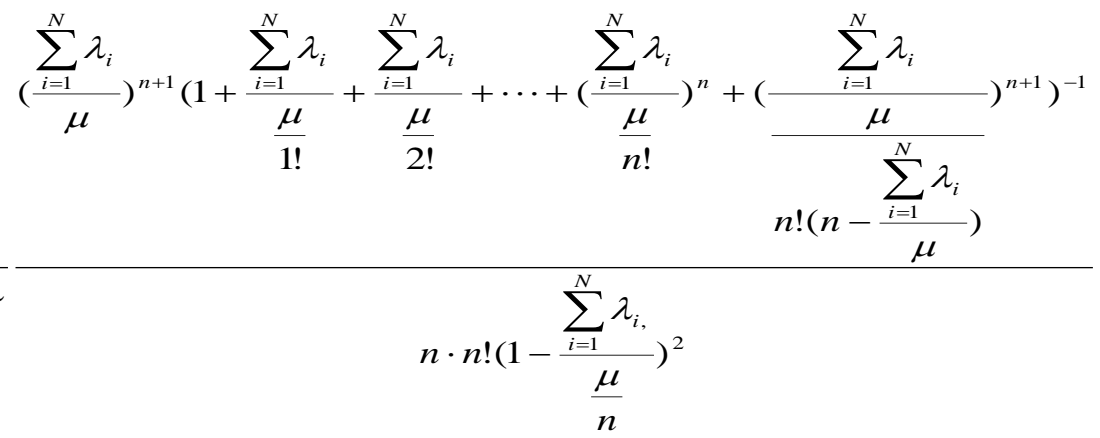

The host device "Master" forwards at odd moments of time while the ancillary device "Slave" does it at even ones. This model has a hierarchical structure since the device, which itself is a host device for each particular network section, can be an ancillary one for another section.

Each of the devices transmits to another one 2 completely different types of traffic.

The "Master" will transmit to a "Slave" a delayinsensitive but bursty and high-volume backup traffic while a "Slave" to the "Master" -- sensitive voice traffic.

An experimental study of this model was conducted using the GPSS tool with $10^{6}$ runs.

Based on the obtained results, it was found that the delay time ratio corresponds to the actually available ratios of network parameters.

A model of infrared traffic has been considered. The purpose of this study is to build a single-channel model of wireless data transmission whose performance would reflect the time and quantitative parameters of data transmission.

A simulation model of a simple version of infrared communication is presented by an open single-channel queuing system.

A transaction that is an indivisible object in a generalpurpose simulation system is generated by a bit moving within the infrared network from an information source to the consumer. The model (of the queuing system) is classified as a $G / M / 1$ model with the $F I F O$ discipline.

The bit delay time in the transmission channels $\left(\mathrm{W}_{\text {queue }}\right)$ of this system will be determined according to the formula for calculating the queuing delay time of a single-channel delay device:

$$
W_{\text {qиеи }}=\frac{L_{\text {qиеие }}}{\sum_{i=1}^{N} \lambda_{i}\left(1-P_{N}\right)}
$$

where $L_{\text {queue }}$ - the average number of transmitted bits is determined by the following formula:

$$
L_{\text {quеие }}=\sum_{i=1}^{N} n P_{n} \text {, }
$$

where $P_{n}-$ the likelihood that an infrared datatransmission channel contains $n$ bits; it is determined by the following formula:

$$
P_{n}=P_{0} \sum_{i=1}^{N} \rho_{i}{ }^{n},
$$

$P_{0}$ - the likelihood that a subchannel is currently busy; it is determined by the following formula:

$$
P_{0}=\frac{1-\sum_{i=1}^{N} \rho_{i}{ }^{n}}{1-\sum_{i=1}^{N} \rho_{i}{ }^{(n+1)}},
$$

where $\rho$ - the load on the wireless data-transmission network, which is determined by the formula (2).

Substituting these values into the formula (3) we obtain the following resulting formula: 


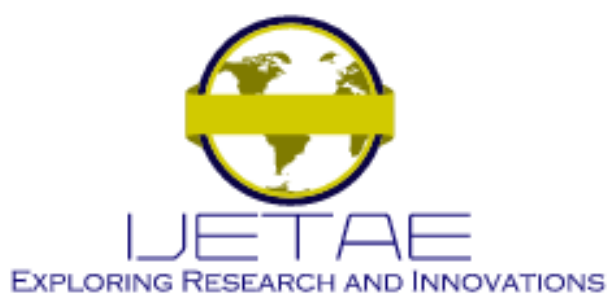

International Journal of Emerging Technology and Advanced Engineering Website: www.ijetae.com (E-ISSN 2250-2459, Scopus Indexed, ISO 9001:2008 Certified Journal, Volume 12, Issue 01, January 2022)

$$
W_{\text {queuе }}=\frac{\sum_{n=0}^{N} n \frac{1-\frac{\sum_{i=1}^{N} \lambda_{i}}{\mu}}{1-\left(\frac{\sum_{i=1}^{N} \lambda_{i}}{\mu}\right)^{(N+1)}}\left(\frac{\sum_{i=1}^{N} \lambda_{i}}{\mu}\right)^{n}}{\sum_{i=1}^{N} \lambda_{i}\left(1-P_{N}\right)} .
$$

As a result of simulation, the network operation parameters were obtained, in particular the queuing delay of the transmission channels of both devices, which corresponds to the transmission channel capacity in case when the load on this channel is maximal.

\section{RESEARCH RESULTS}

The standards of the IEEE 802.11 type network have been studied using one or another queuing discipline, which is set by applying one of the queue management algorithms. The main task of these studies is to model a multi-channel wireless data-transmission network using various queue management algorithms, determine in practice an optimal data-transmission management algorithm using comparative characteristics. The algorithms used for modeling are randomized without being bound to real devices.

Queue management algorithms are required to operate during periods of temporary congestion at maximum load of the wireless network transmission channels if the network device cannot cope with forwarding bits to the output interface at the rate at which they arrive. If the cause of congestion lies in underperformance of the processing unit of the wireless network device, then raw bits are temporarily accumulated in the input queue of the corresponding input interface. There may be several queues for the input interface if service requests are differentiated by several classes. There can be several input interface queues if service requests are differentiated by several classes. In the event that congestion is due to limited capacity of the output interface, bits are temporarily stored in the output queue (or queues) of this interface.

Conceptual models of networks using various queue management algorithms in IEEE 802.11 protocol networks are represented by an open multiphase queuing system. A transaction, which is an indivisible object within the general-purpose simulation system, was generated by a bit moving in an IEEE 802.11-type network from the information source to the consumer.
Each phase was modeled by QS GMNn built according to the conditions of some queue management algorithm or other. Formula 1 will be the resulting formula for determining the bit delay time in the transmission channels $\left(W_{\text {queue }}\right)$ of this network because the model of this network is also presented in the form of a multichannel delay QS. The model consists of workstations and a wireless access point. Let us de describe operation of this system: bits arriving from the workstation that transmits data, line up for service for the access point. Next, the line up at the access point for distribution to the workstations that are their recipients. Then they stand in line for processing to the intended recipient.

\section{ANALYSIS Of THE RESEARCH RESUlTS}

Three models of an appropriate structure in which 3 different traffic management algorithms applied in different IEEE 802.11 standards have been considered:

- “FIFO”;

- "Priority-service discipline";

- "Weighted queuing”.

A study was conducted to compare these algorithms under the following criteria:

- capacity of transmission channels;

- maximum data transmission rate;

- data transmission distance; and

- number of subchannels.

Based on a series of comparative studies conducted under to the rules of procedure for supporting decisionmaking "Analytic hierarchy process" (AHP), the following final coefficients have been obtained concerning these:

- "FIFO" algorithm - 0.228;

- "priority-service discipline” algorithm - 0.222;

- “Weighted queuing” algorithm - 0.55.

As a result of these comparisons, it was established that the "weighted queuing" algorithm is twice as good as the other two.

A number of studies have shown that the results obtained using a G/M/n-type model to simulate data transmission of wireless computer networks are the most accurate among other types of models.

Experimental studies have been performed on the models described in the previous section.

The wireless network model was studied at the conceptual level. 


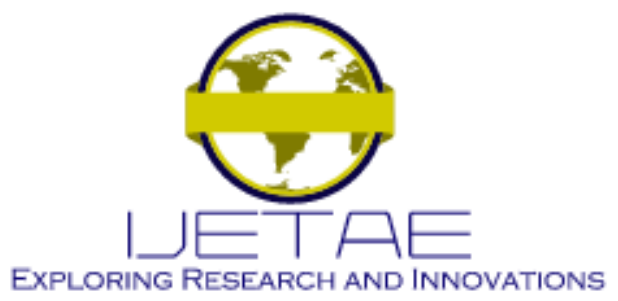

International Journal of Emerging Technology and Advanced Engineering

Website: www.ijetae.com (E-ISSN 2250-2459, Scopus Indexed, ISO 9001:2008 Certified Journal, Volume 12, Issue 01, January 2022)

Based on the results of simulating this network at the standard frequency band of the "Bluetooth" network

(2400 - 2483.5 MHz ISM-bandwidth), the characteristic shown in Figure 1 was obtained using formula (1).

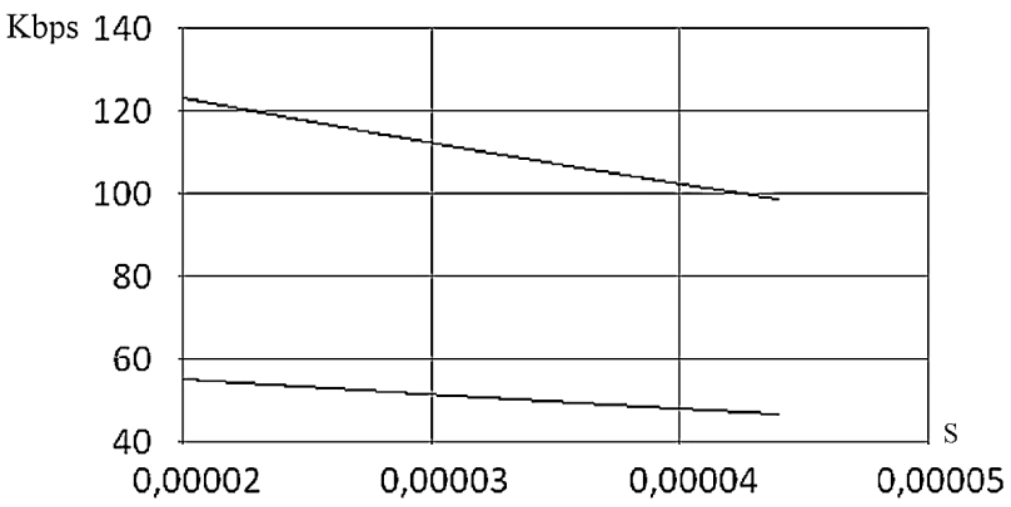

Figure 1. Graph of Dependency of the Transmission Channel Capacity on the Processing Delay Time

The standard frequency band was extended by $80 \mathrm{MHz}$, and the characteristic shown in Figure 1 was measured under formula (1).

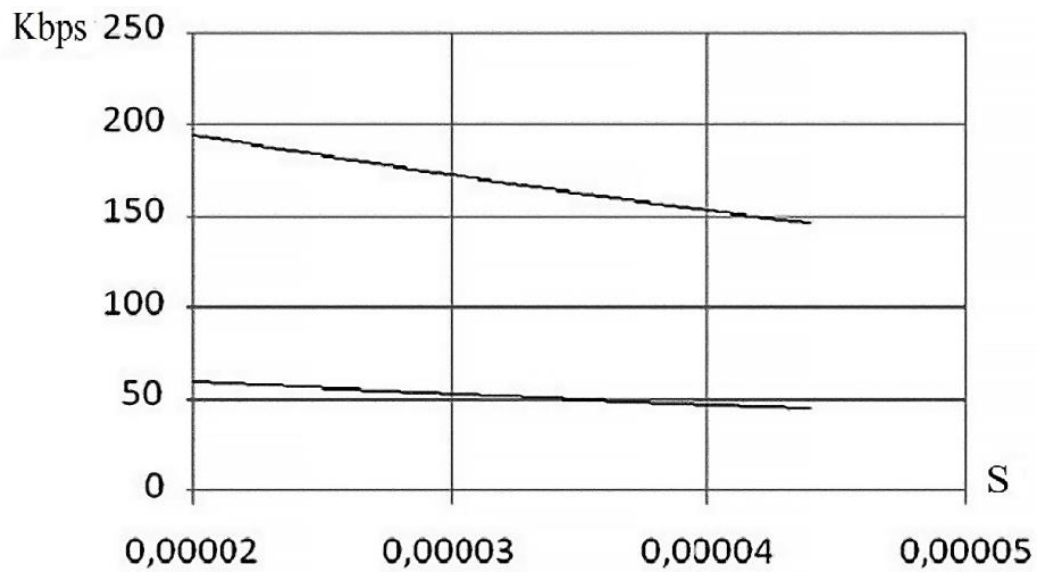

Figure 2. Graph of dependency of the transmission channel capacity on the processing delay time with an extended freaquancy band

It has been concluded, as a result, that although the frequency band extension worsens at first the data transmission speed indicators of the Bluetooth wireless network, but it significantly improves other parameters. In particular, the Bluetooth-type network capacity.
An infrared data-transmission network has been investigated. Data transmission in this case will occur from one device to another. In this study, we will trace the dependence of a transmission channel capacity (C) on the traffic processing delay time in the channel server that is shown in Figure 3 and obtained under formula (3). 


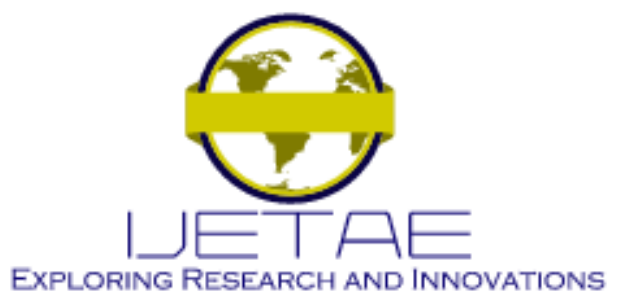

International Journal of Emerging Technology and Advanced Engineering Website: www.ijetae.com (E-ISSN 2250-2459, Scopus Indexed, ISO 9001:2008 Certified Journal, Volume 12, Issue 01, January 2022)

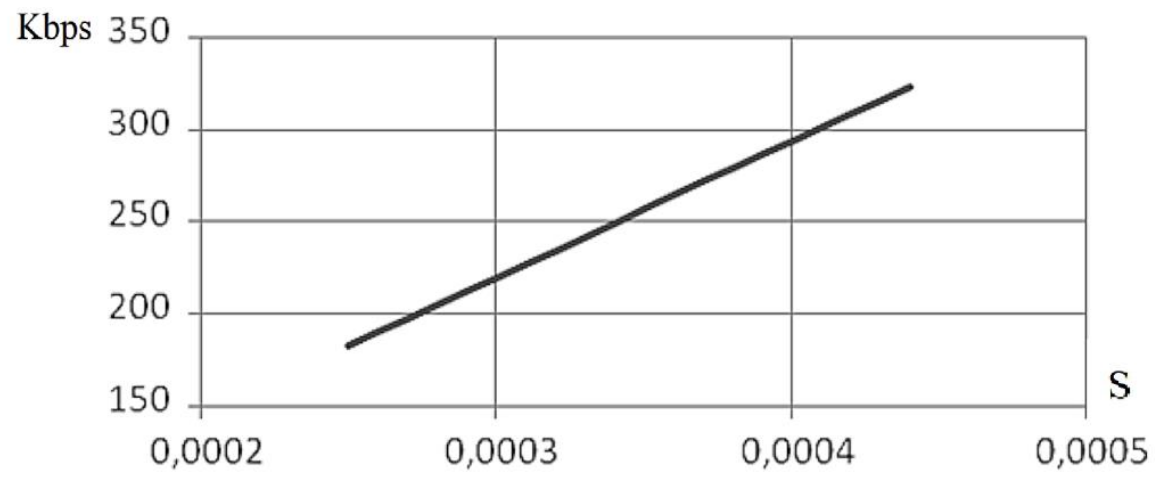

Figure 3. Graph of Dependency of the Transmission Channel Capacity on the Traffic Processing Delay Time in the Channel Server

This graph shows a linear growth of the load, which indicates a stable behavior of servers when simulating stationary processes using models such as $G / M / 1$.

\section{DISCUSSION. COMPARISON OF THE SUGGESTED ALGORITHMS WITH THE EXISTING ONES}

Studies of the standards of the IEEE 802.11 protocol network with the use of various queue management algorithms have been carried out.
Dependences of capacity on the delay time were also constructed.

The main feature that distinguishes these studies from previous ones consists in algorithms for functional integration of the lower layers of the $O S I$ reference model.

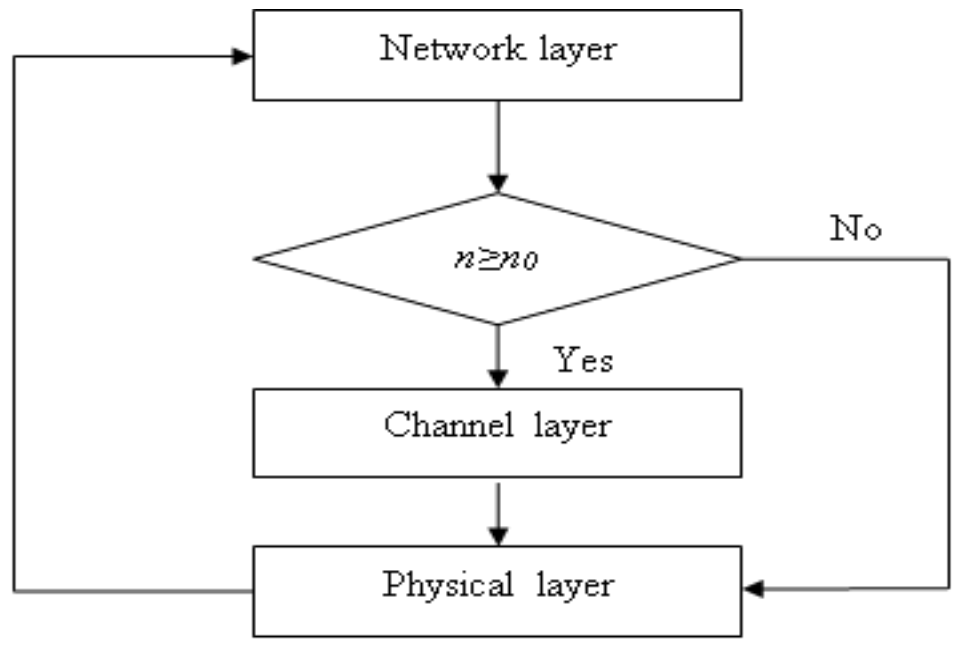

Figure 4. Control Flow Chart of the Signal Quality State Analysis

This technology was applied to study networks of the IEEE 802.11 standard using the above three algorithms. This made it possible to obtain, according to formula 5 , the following results shown in Figures 6, 7.

The algorithm is based on controlling the bits of the physical layer frame. It is developed in order to obtain necessary information from the fields that contain information on the data transmission medium.
In this method, the network layer, at specific time intervals, sends requests for the physical state of the signal at the moment. The signal state information is contained in a field in which the first bits contain information on the transmission rate while the others - on the signal state.

Usually, each of the above signal states corresponds to a number from 0 to 6 . 


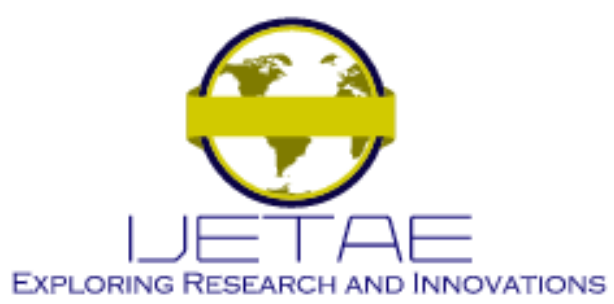

International Journal of Emerging Technology and Advanced Engineering Website: www.ijetae.com (E-ISSN 2250-2459, Scopus Indexed, ISO 9001:2008 Certified Journal, Volume 12, Issue 01, January 2022)

Based on the obtained data, the network layer forms an idea of the change of communication statuses, constantly comparing the current and previous statuses $\left(n<n_{0}\right.$ or $n \geq$ $n_{0}$ ). In case when a change of statuses corresponds to $n<$ $n_{0}$, the network layer sends a repeated request. This cycle will continue until the situation becomes the opposite $(n \geq$ $n_{0}$ ) (branch "yes"). Only then the network layer will send a packet to the datalink layer and give an order to transmit it. Then the datalink layer, if there is an idle channel, will order the physical layer to generate bits in accordance with a specific packet.
The specifics of this algorithm were taken into account in the flow diagram of the wireless data transmission device of the line, which would perform the function of communication between the applications of the physical and network layers of the OSI reference model OSI. That is, it would work on the basis of this algorithm. For this very reason, a signal quality analyzer 5 (Figure 5) is introduced into the existing flow diagram of the wireless communication device.

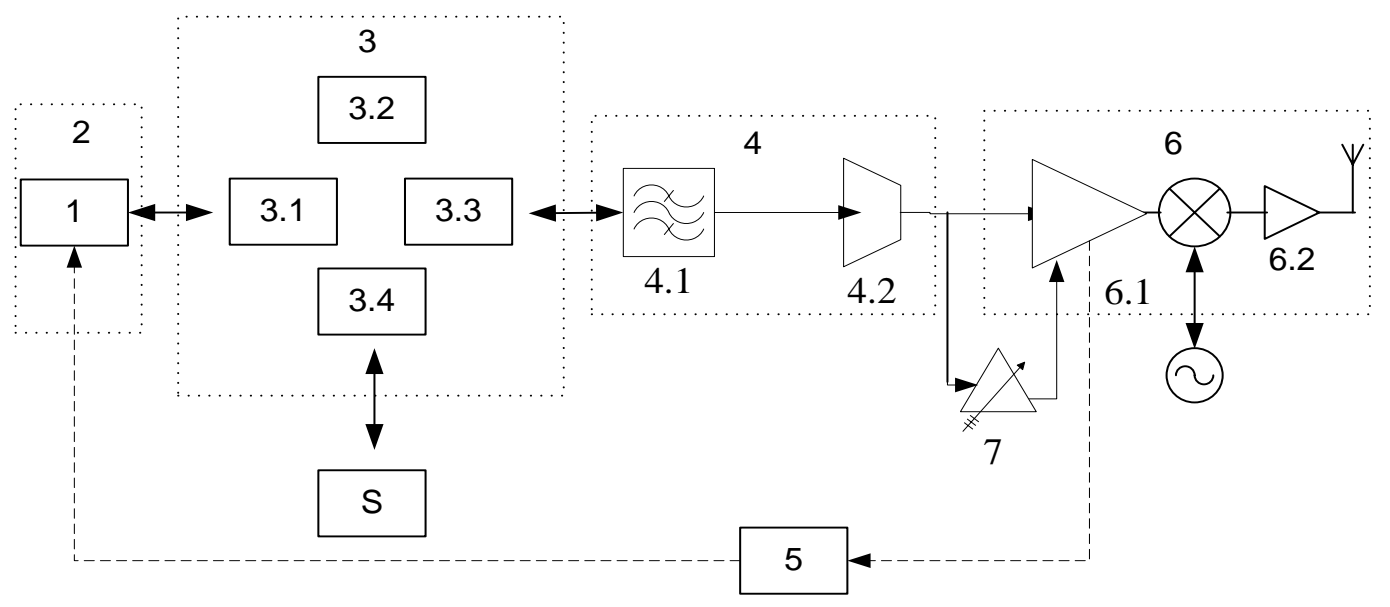

Figure 5. Flow Diagram of the Data Transmission Device in Wireless Networks of the Standard with a Performance Enhancement System in Marginal Reception Areas or those with Insufficient Noise Immunity

When building up the device, its blocks are divided into modules, according to their belonging to a particular layer of the reference model. The device contains the control block 1, which is part of the $N M S$, network layer module 2, module of the $L L C$ sublayer of model datalink layer 3, host interface block 3.1, integrated microcontroller 3.2, transceiver application block 3.3, bus interface block 3.4, memory S, MAC sublayer module of the datalink layer 4, frequency band controller 4.1, radio frequency transceiver 4.2, signal analyzer 5, physical layer module 6 , physical layer interface 6.1, antenna 6.2, and the automatic frequency adjustment block 7 .

The principle of operation of this device is given. In the LLC sublayer module, a packet becomes a frame through the host interface block 3.1, having undergone appropriate transformations, using the applications of this module. Thereafter, the integrated microcontroller 3.2 transmits the frame to the transceiver application block 3.3 and through the bus interface block 2.4 writes data on the transmission state in memory $\mathrm{S}$ where it is stored for some time.
The transceiver application block 3.3 directs the frame to the sublayer module 4.

In the MAC sublayer module, the frequency band controller 4.1 selects an optimum frequency range for a given frame and directs the frame to the radiofrequency transceiver 4.2. In this module, there occurs both conversion of the frame into electromagnetic oscillations and their modulation according to the content of the frame. After that, oscillations are transmitted to the physical layer module 6 , while information on the frequency range selected by block 4.1 is transmitted to the automatic frequency adjustment block 7 .

The block 6.1 of the physical layer module imposes electromagnetic oscillations on the frequency that is adjusted by block 7 . Oscillations are directed to the antenna 6.2 , which transmits the signal to the airwaves.

The signal analyzer 5 constantly keeps track of the information on the data transmission state. It submits appropriate requests to the physical layer interface 6.1 and receives from it information on the data transmission state. 


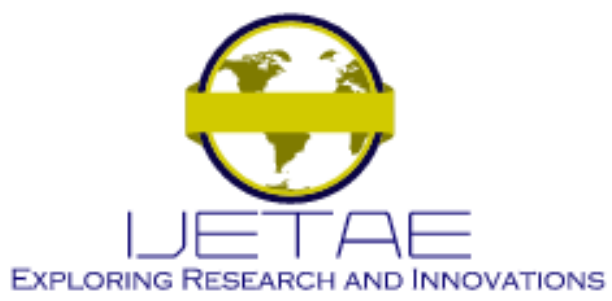

International Journal of Emerging Technology and Advanced Engineering Website: www.ijetae.com (E-ISSN 2250-2459, Scopus Indexed, ISO 9001:2008 Certified Journal, Volume 12, Issue 01, January 2022)

The signal analyzer 5 transmits information on the data transmission state to the control device 1 , after which a decision is made to change the conditions for data transmission, as may be necessary.
Decision-making means waiting for the signal quality improvement (according to the algorithm rules) or increasing its power by reducing the speed (proceeding to the packet binary encoding).

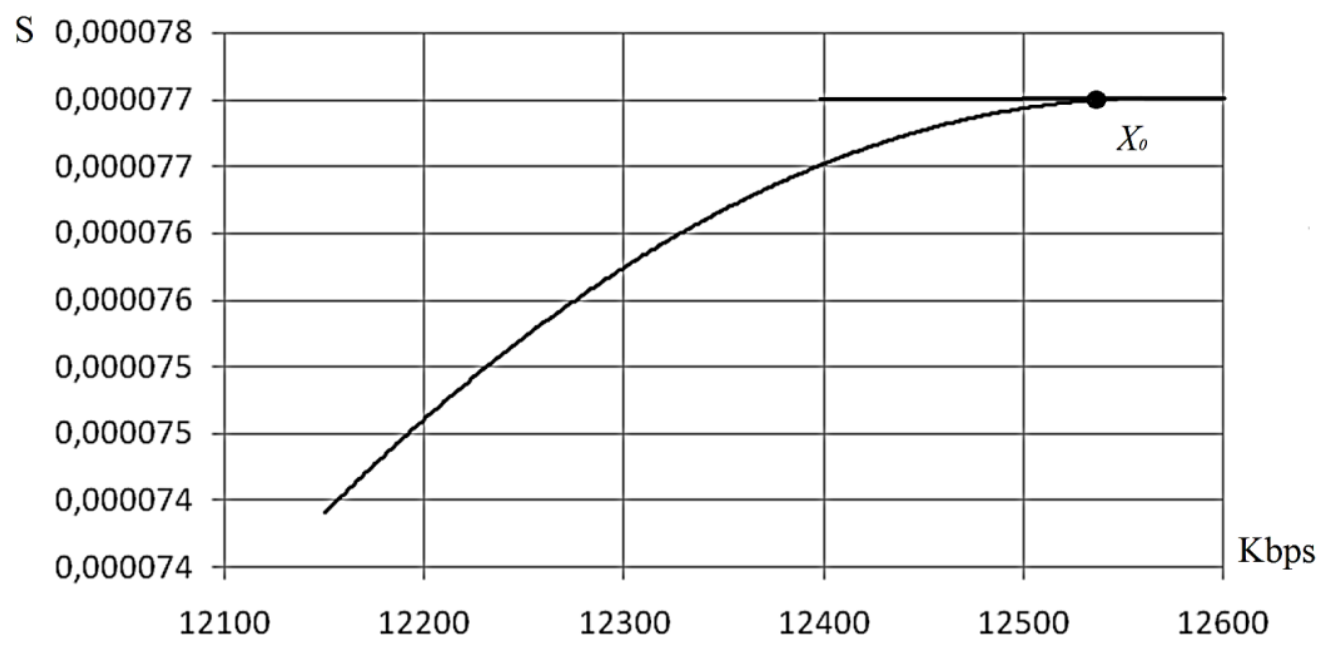

Figure 6. Graph of Dependency of the Delay Time on the Transmission Channel Load

The saturation point $\mathrm{X} 0$ is determined by the formula:

$$
X_{0}=\frac{1}{V_{d} R_{d}},
$$

where $X_{0}$ - the heaviest load for this network;

$V_{d}$ - attendance ratio for node the $d$;

$R_{d}$ - bits stay time in the network for the node $d$.

The data transmission rate used in the simulation corresponded to the Peak Cell Rate (PCR) -- the maximum data transmission rate is $54 \mathrm{Mbit} / \mathrm{s}$.
In the wireless transmission channels of this network, redistribution of flows will take place using the queue management algorithm "Weighted queuing." That is, distribution of bits of information in the transmission channels will occur in accordance with the percentage of capacity allocated to this traffic class. The percentage of capacity is allocated to a particular traffic class according to its priority.

An experiment was performed according to the above algorithm.

Based on these studies, according to the formula (1), the characteristic shown in Figure 6 was generated. 


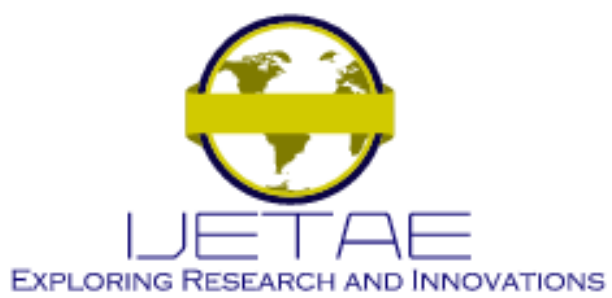

International Journal of Emerging Technology and Advanced Engineering Website: www.ijetae.com (E-ISSN 2250-2459, Scopus Indexed, ISO 9001:2008 Certified Journal, Volume 12, Issue 01, January 2022)

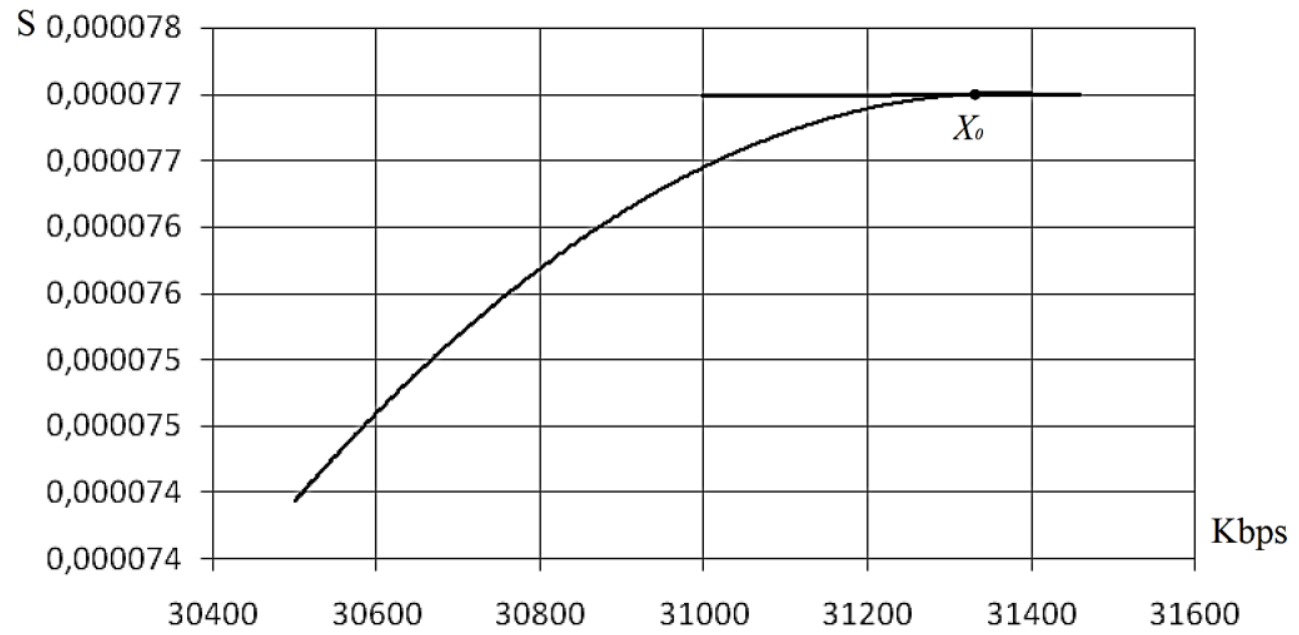

Figure 7. Graph of Dependency of the Delay Time on the Transmission Channel Load

As shown in the graph, this algorithm makes quite positive changes in the wireless network operation. This is evidenced by the fact that with a significant increase in the load in the transmission channels, the delay time of the bits in the process queue was largely the same. That is, these algorithms improved almost threefold the speed characteristics of the network operation. It is quite probable that such an improvement is due to the reduction in the percentage of erroneous packets and requests for their resending, which also take some time to process, as well as the transition to a higher power standard when the signal strength drops, which undoubtedly improves the network operation stability considerably reducing the likelihood of no signal in marginal reception areas.

\section{CONCLUSIONS}

The reigning feature of the methods for data transmission control of wireless information systems consists in limited capacity of the system and the unlimited noise influence on the data transmission medium from external sources emitting super-high frequencies. A possible reduction in the network capacity can reach $90 \%$ compared to the same case in cable-based networks.

Simulation of queue management algorithms in wireless information systems made it possible to find out that in case of using the "Weighted queuing" algorithm the aggregate capacity is $9 \mathrm{Mbit} / \mathrm{s}$ better than when using other algorithms.
The following solutions to the problem of improving the quantitative and qualitative characteristics of wireless data transmission were found: expanding the frequency band of the short-range network allows improving the network capacity by almost 50\%; a method for improving performance of wireless networks is suggested that functionally combines the physical and network layers, which can improve the network capacity in marginal reception areas almost twice; the weighted service algorithm for traffic requests of wireless computer networks is the most effective technology of data transmission in wireless computer networks; provided the degree of inaccuracy of output data is 0.9 and on its basis, the method "Reallocation of capacity of a wireless network transmission channel" improving service quality is suggested.

\section{REFERENCES}

[1] M.E. Helou, M. Ibrahim, S. Lahoud, K. Khawam, D. Mezher, and B.A. Cousin, "A network-assisted approach for rat selection in heterogeneous cellular networks", IEEE Journal on Selected Areas in Communications, vol. 33, no. 6, pp. 1055-1067, 2015.

[2] G. Yu, Y. Jiang, L. Xu, and G. Li, "Multi-objective energy-efficient resource allocation for multi-rat heterogeneous networks", IEEE Journal on Selected Areas in Communications, vol. 33, no. 10, pp. 2118-2127, 2015.

[3] K.-L. Chiu, Y.-Sh. Chen, and R.-H. Hwang, "Seamless session mobility scheme in heterogeneous wireless networks", International Journal of Communication Systems, vol. 24, no. 6, pp. 789-809, 2011. 


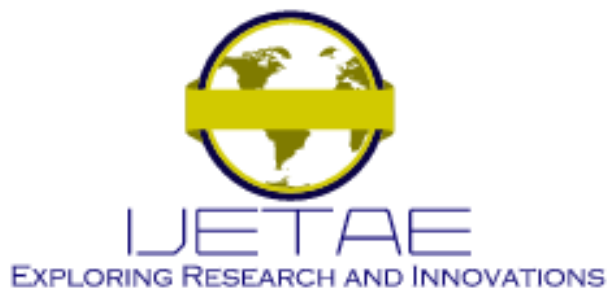

\section{International Journal of Emerging Technology and Advanced Engineering}

\section{Website: www.ijetae.com (E-ISSN 2250-2459, Scopus Indexed, ISO 9001:2008 Certified Journal, Volume 12, Issue 01, January 2022)}

[4] K. Naidu, and R.B. Battula, "Quicker solution to reduce interference in wireless networks", IET Communications, vol. 12. No. 14, pp. 1661-1670, 2018. https://doi.org/10.1049/iet-com.2017.0684

[5] W. $\mathrm{Xu}$, and $\mathrm{H}$. Zhang, "Uplink interference mitigation for heterogeneous networks with user-specific resource allocation and power control", EURASIP Journal on Wireless Communications and Networking, vol. 2014, no. 1, p. 55, 2014

[6] K. Khawam, S. Lahoud, M. Ibrahim, M. Yassin, S. Martin, M.E. Helou, and F. Moety, "Radio access technology selection in heterogeneous networks", Physical Communication, vol. 18, no. P2, pp. 125-139, 2016.

[7] H. Zhang, Ch. Jiang, N. Beaulieu, X. Chu, X. Wang, and T.Q.S. Quek, "Resource allocation for cognitive small cell networks: A cooperative bargaining game theoretic approach", IEEE Transactions on Wireless Communications, vol. 14, no. 6, pp. 34813493, 2015.

[8] M. Vu, "Miso capacity with per-antenna power constraint", IEEE Transactions on Communications, vol. 59, no. 5, pp. 1268-1274, 2011.

[9] R. Zhang, "Cooperative multi-cell block diagonalization with perbase-station power constraints", IEEE Journal on Selected Areas in Communications, vol. 28, no. 9, pp. 1435-1445, 2010.

[10] Z. Burinska, K. Runovski, and H.-J. Schmeisser, "On the approximation by generalized sampling series in lp - metrics", Sampling Theory in Signal and Image Processing, vol. 5, no. 1, pp. 59-87, 2006

[11] M.P. Leshchenko, A.M. Kolomiiets, A.V. Iatsyshyn, V.V. Kovalenko, A.V. Dakal, and O.O. Radchenko, "Development of informational and research competence of postgraduate and doctoral students in conditions of digital transformation of science and education", Journal of Physics: Conference Series, vol. 1840, no. 1, 012057, 2021. https://doi.org/10.1088/1742-6596/1840/1/012057

[12] I.S. Zinovieva, V.O. Artemchuk, A.V. Iatsyshyn, O.O. Popov, V.O. Kovach, A.V. Iatsyshyn, and O.V. Radchenko, "The use of online coding platforms as additional distance tools in programming education", Journal of Physics: Conference Series, vol. 1840, no. 1, 012029, 2021. https://doi.org/10.1088/1742-6596/1840/1/012029

[13] L. Shytyk, and A. Akimova, "Ways of transferring the internal speech of characters: Psycholinguistic projection", Psycholinguistics, vol. 27, no. 2, pp. 361-384, 2020. https://doi.org/10.31470/2309-1797-2020-27-2-361-384

[14] A.V. Iatsyshyn, V.O. Kovach, V.O. Lyubchak, Y.O. Zuban, A.G. Piven, O.M. Sokolyuk, A.V. Iatsyshyn, O.O. Popov, V.O. Artemchuk, and M.P. Shyshkina, "Application of augmented reality technologies for education projects preparation", in Proceedings of the 7th Workshop on Cloud Technologies in Education (CTE 2019), Kryvyi Rih, Ukraine, December 20, 2019, pp. 134-160.

[15] O. Pysarchuk, A. Gizun, A. Dudnik, V. Griga, T. Domkiv, and S. Gnatyuk, "Bifurcation prediction method for the emergence and development dynamics of information conflicts in cybernetic space", in Proceedings of the International Workshop on Cyber Hygiene (CybHyg-2019), co-located with 1st International Conference on Cyber Hygiene and Conflict Management in Global Information Networks (CyberConf 2019), Kyiv, Ukraine, November 30, 2019, pp. 692-709.
[16] A. Dudnik, V. Kvasnikov, O. Trush, and T. Domkiv, "Development of distributed multi-segment wireless networks for determining external situations", in Proceedings of the 7th International Conference "Information Technology and Interactions" (IT\&I-2020). Workshops Proceedings, Kyiv, Ukraine, December 02-03, 2020, pp. 127-137.

[17] A. Rokochinskiy, P. Volk, L. Kuzmych, V. Turcheniuk, L. Volk, and A. Dudnik, "Mathematical model of meteorological software for systematic flood control in the Carpathian region", in 2019 IEEE International Conference on Advanced Trends in Information Theory (ATIT). IEEE, 2019, pp. 143-148.

[18] A. Dudnik, L. Kuzmych, O. Trush, T. Domkiv, O. Leshchenko, and V. Vyshnivskyi, "Smart home technology network construction method and device interaction organization concept", in 2020 IEEE $2^{\text {nd }}$ International Conference on System Analysis \& Intelligent Computing (SAIC). IEEE, 2020, pp. 1-6. https://doi.org/10.1109/SAIC51296.2020.9239220

[19] T. Domkiv, A. Dudnik, N. Dakhno, V. Kvasnikov, O. Trush, and S. Dorozhynskyi, "Development of an all-based method using blockchain technologies and cuda technologies", in 2020 IEEE $2^{\text {nd }}$ International Conference on Advanced Trends in Information Theory (ATIT). IEEE, 2020, pp. 200-205.

[20] A. Dudnik, D. Pokutnia, M. Kobylchuk, T. Domkiv, N. Dahno, and O. Leshchenko, "Intrusion and fire detection method by wireless sensor network", in 2020 IEEE 2nd International Conference on Advanced Trends in Information Theory (ATIT). IEEE, 2020, pp. 211-215.

[21] O. Leshchenko, O. Trush, N. Dahno, A. Dudnik, K. Kazintseva, and O. Kovalenko, "Methods for predicting adjustments to the rates of modern "Digital money",", in 2020 IEEE 2nd International Conference on Advanced Trends in Information Theory (ATIT). IEEE, 2020, pp. 222-226.

[22] O. Barabash, N. Shevchenko, N. Dakhno, Y. Kravchenko, and O. Leshchenko, "Effectiveness of targeting informational technology application", in IEEE International Conference on System Analysis \& Intelligent Computing (SAIC'2020). IEEE, 2020, pp. 193-196.

[23] O.A. Mashkov, R.K. Murasov, Y.V. Kravchenko, N.B. Dakhno, O.A. Leschenko, and O.V. Trush, "Optimal forecast algorithm based on compatible linear filtration and extrapolation", Mathematical Modeling And Computing, vol. 8, no. 2, pp. 157-167, 2021.

[24] Y. Kravchenko, O. Afanasyeva, M. Tyshchenko, and S. Mykus, "Intellectualisation of decision support systems for computer networks: Production-logical F-Inference", in Proceedings of the 7th International Conference "Information Technology and Interactions" (IT\&I-2020). Workshops Proceedings, Kyiv, Ukraine, December 0203, 2020, pp. 117-126.

[25] Y. Kravchenko, N. Dakhno, O. Leshchenko, and A. Tolstokorova, "Machine learning algorithms for predicting the results of COVID19 coronavirus infection", in Proceedings of the 7th International Conference "Information Technology and Interactions" (IT\&I-2020). Workshops Proceedings, Kyiv, Ukraine, December 02-03, 2020, pp. $371-381$. 